\title{
Erratum to: Evaluation of anterior knee pain in a PS total knee arthroplasty: the role of patella-friendly femoral component and patellar size
}

\author{
F. Atzori $\cdot$ L. Sabatini $\cdot$ D. Deledda $\cdot$ \\ M. Schirò • R. Lo Baido • A. Massè
}

Published online: 21 March 2015

(C) Istituto Ortopedico Rizzoli 2015

Erratum to: Musculoskelet Surg

DOI 10.1007/s12306-015-0347-2

In the original publication of this article, one of the coauthors' (Roberto Lo Baido) family name has been published incorrectly. The correct family name should be Lo Baido.

The online version of the original article can be found under doi:10.1007/s12306-015-0347-2.

F. Atzori $(\bowtie) \cdot$ L. Sabatini · A. Massè

Unit of Orthopaedics and Traumatology, Hospital San Luigi

Gonzaga, University of Turin, Regione Gonzole 10, Orbassano,

10043 Turin, Italy

e-mail: f_atz@libero.it

D. Deledda · M. Schirò $\cdot$ R. Lo Baido

University School of Orthopaedics and Traumatology,

University of Turin, Turin, Italy 